\title{
Mesenchymal/proangiogenic factor YKL-40 related to glioblastomas and its relationship with the subventricular zone
}

\author{
Kelvin M. Piña Batista ${ }^{1}$, Sayoa Alvarez de Eulate-Beramendi ${ }^{1}$, Kenia Y. Álvarez Reyes de Piña², \\ Pedro Reimunde Figueira ${ }^{1}$, Adan Fernandez Canal ${ }^{1}$, Josué M. Avecillas Chasin ${ }^{3}$, Ángela Meilan ${ }^{1}$, Rodrigo Ugalde ${ }^{1}$, \\ Ivan Fernandez Vega ${ }^{1}$ \\ ${ }^{1}$ Department of Neurosurgery, Hospital Universitario Central de Asturias, Asturias, ${ }^{2}$ Hospital Vital Alvarez Buylla, Asturias, \\ ${ }^{3}$ Hospital Universitario Joan XXIII, Tarragona, Spain
}

\begin{abstract}
Glioblastoma is the most common primary brain tumor. Despite multimodality therapy with aggressive microsurgical resection and adjuvant chemotherapy and radiotherapy, the median survival is below 15 months. Glioblastomas are heterogeneous tumors with high resistance to most chemotherapeutic drugs. According to reliable evidence, YKL-4O, one of the best investigated chitinase-like protein, may facilitate invasion, migration and angiogenesis, and could be also responsible for temozolomide resistance in glioblastoma, thus conferring a dismal prognosis. Previous studies have demonstrated that glioblastoma stem cells give rise to endothelial cells through an YKL-40 influence. Such factor is closely related to the subventricular zone. This review focuses on the most recent theories involving the possible relationship between topographic gliomagenesis related to the subventricular zone and YKL-4O.
\end{abstract}

Key words: glioblastoma, subventricular zone, YKL-40, glioblastoma stem cells.

\section{Introduction}

Glioblastoma (GB) is the most common primary malignant brain tumor in adults [6,86], accounting for more than $45 \%$ of primary malignant brain tumors. Glioblastoma has an incidence that increases with age and peaks between 75 and 84 years old, being more common in white males, according to the most recent Central Brain Tumor Registry of the United States (CBTRUS) statistical report. The median survival for patients diagnosed with GB using the current standard of care is only 12 to 15 months $[8,52,77,81]$ despite multimodality treatment with aggressive microsurgical resection, combined radiation and chemotherapy, and adjuvant chemotherapy [81]. GB cells are diffusely infiltrative and motile; consequently, GB renders them incurable by surgery alone $[24,78,79]$. Thus, a novel therapeutic approach is urgently needed to control recurrence and overcome resistance to treatment.

Over the last few decades, it has become clear that GBs are characterized by an extreme degree of phenotypic, cellular, genetic, epigenetic, and radiological heterogeneity, as implied by the older term "multiforme" [37,73], which challenges our ability 
to understand or treat it. There have been several studies that seek to determine which factors can be prognostic or predictive to impact on overall survival and progression free survival $[3,19,33,41,46,53,55]$.

Although currently more research is needed, biomarkers must be taken into account when deciding which treatment modality is most appropriate for the individual patient. We review the evidence and theories involving the possible relationship between topographic gliomagenesis related to the subventricular zone (SVZ) and YKL-40, in an attempt to reveal either cellular mechanisms or molecular factors associated with ubiquitous GB stem-like cells (GSCs) support and motility. The following aspects are summarized: subventricular zone, mesenchymal factor YKL-40, radial glia and the perivascular tumor cells.

Levels of circulating, subgranular or subventricular YKL-40 (chitinase 3-like 1 or cartilage glycoprotein-39), have the potential to be used in the optimization of glioblastoma therapies. Elevated serum levels of YKL-40 were found in $55-75 \%$ of patients with GB with shorter OS [6,7,29,31].

One of the most recent and attractive evidence included YKL-40 as the most predictive and prognostic marker in patients with GB $[15,87]$, and it has been shown directly associated with tumor radioresistance, invasiveness, migration, recurrence, chromosome 10 loss $[6,29,54]$, hypoxia-induced mesenchymal transition [36], and poor clinical outcome prognosis. Recently, Akiyama et al. using a TMZ-resistant (TMZ-R) U87 GB cell in vitro and in vivo identified that YKL-40 could be also responsible for temozolomide resistance in GB and suggested that therapies targeting YKL-40 may be potentially beneficial in GB treatment [2].

\section{Glioblastoma stem cells and YKL-40}

Glioblastoma is composed of cancer cells and surrounding stromal cells with diverse genetic/epigenetic backgrounds. Increasing evidence suggests that the tumorigenic process in GB is apparently initiated and maintained by a rare and special subpopulation of slow-cycling clonogenic cells referred to as GSCs $[28,62,66,67]$. It has been assumed that overall survival heterogeneity $[33,45,46]$ in patients with GB might be related to GSCs variability and brain microenvironment [58]. Presently, it is not clear what the origin of GSCs is, but presumably it may arise from SVZ stem cells. Based on in vivo evidence, GSCS are responsible for tumor growth, recurrence, and resistance to therapies $[15,48,59]$ and endowed with unregulated self-renewal, robust proliferative potential, high motility, diversity of progeny association with blood vessels and white matter tracts, multi-lineage differentiation capacities, invasiveness [22,63], and relatively resistant to radio- and chemotherapies [56,80], which express markers of both undifferentiated and differentiated cells [73], with a similar behavior to neural stem cells (NSCs) [5], which are present during the early development of the brain [7]. Nevertheless, the specific intrinsic factors that govern such characteristics are not well understood [27,66,83].

Mounting evidence shows that GSCs are largely dependent on distinctive and specialized vascular, perivascular or perinecrotic microenvironment called "niche" $[11,30,63,64,66,68,76]$. Furthermore, some investigators observe that GSCs give rise to endothelial cells (ECs)60, as shown in Figure 1, and induce changes in vascular niches, characterized by the sprouting of new blood vessels, consisting of an abundant, leaky and highly disorganized "glomeruloid" vascular network through the cooperative secretion of pro-angiogenic factors $[1,61,67]$, such as VEGF, IL-8 and YKL-40 [2,29,56], highly different in patients with the same tumor $[42,56,60,82]$. YKL-40, also known as chitinase-like protein 1 or human cartilage glycoprotein-39 [6], is a highly conserved glycoprotein that belongs to the glycosyl hydrolase family 18 with no chitinolytic activity [7,84], included as a mesenchymal marker overexpressed in $\mathrm{GB}$ and postulated as one of the most promising predictive serum markers since it was found to have elevated levels in the serum of patients with GB $[6,29,31,32,35]$.

So far, YKL-40 has been found to induce tight interplay between the membrane receptors syndecan-1 and an adjacent membrane-associated protein integrin $\alpha v \beta 5$ [21] on endothelial cells [70,71], and triggered a signaling cascade through pFAK $[8,61]$ to MAP kinase ERK-1 and ERK-2 by regulating VEGF expression and inducing angiogenesis as an independent angiogenic factor under hypoxic conditions.

However, these vascular formations usually lack basement membrane and pericyte coverage. In addition, recent studies $[1,44,66]$ support that vasculogenesis $[34,56]$ by GSCs may occur directly via 


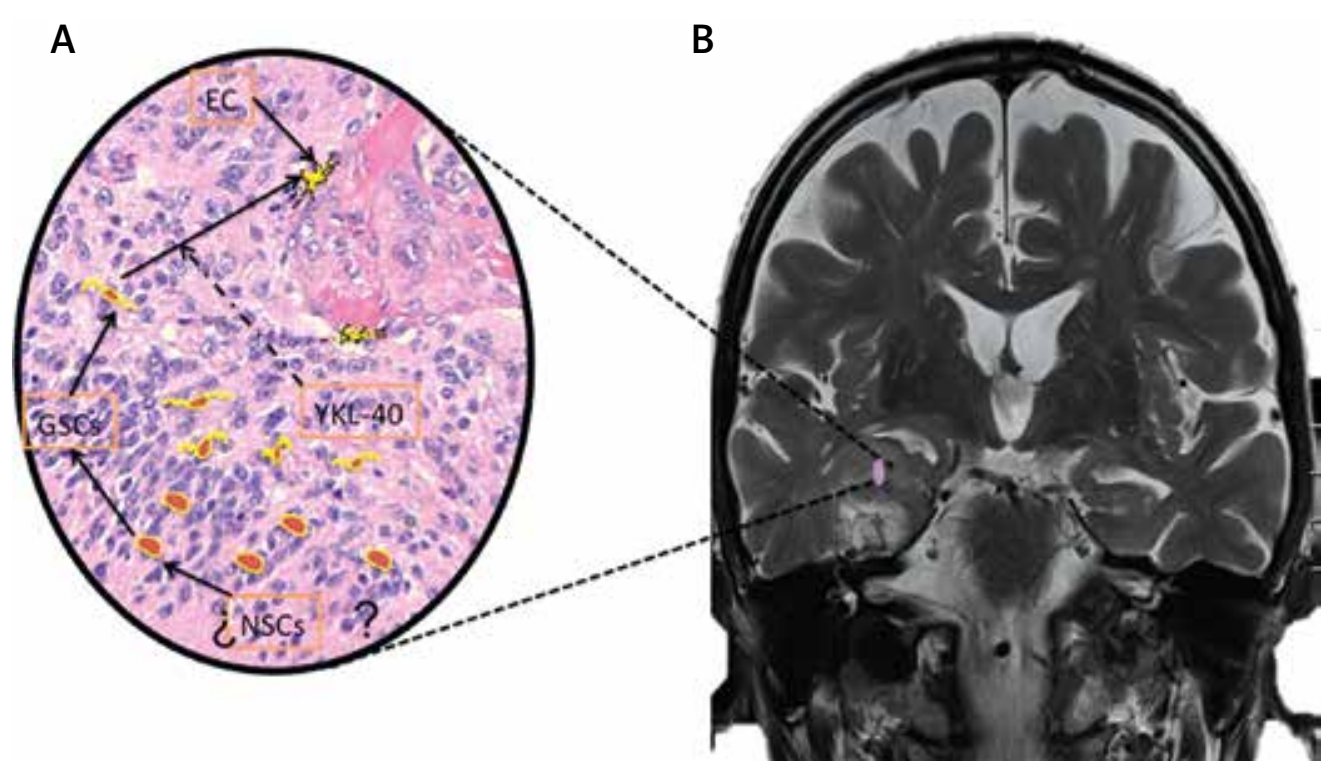

Fig. 1. Model depicting the glioblastoma stem-like cells (GSCs) transdifferentiation into Ecs. YKL-40 acts as an angiogenic factor to trigger tumor vascular development. B) Magnetic resonance image of a glioblastoma tumor, and (A) tissue sample from the same tumor illustrating tumor microenvironment.

differentiation of cells that participate in vasculogenesis, tumor growth, or indirectly via cytokines and chemokines production stimulated by hypoxia, which are known to activate endothelial cells. Interestingly, through a three dimensional reconstruction, Calabrese et al. demonstrated that brain GSCS are preferentially located in close contact to tumor microvasculature and that endothelial cells release trophic factors that maintain these cells in a selfrenewing and undifferentiated state [12].

As a well-recognized component of the tumor microenvironment, intratumoral low oxygen concentration upregulates the expression of multiple factors such as hypoxia-inducible factors (HIFs), members of a subfamily of basic helix-loop helix transcription factor that regulates different aspects of cell biogenesis such as metabolism, migration, proliferation, differentiation, apoptosis, angiogenesis, resistance to chemotherapy, and stem cell maintenance $[13,14,28,44,50]$. Importantly, recent findings indicate that GSCs are the origin of tumor recurrence in glioblastoma [13,62,83]. Indeed, it has been demonstrated through a genetically-engineered mouse model that after arrest of tumor cell proliferation with temozolomide, the first cell population to undergo proliferation and lead to tumor regrowth is the nestin-positive (a marker also for neural stem cells) GSC population [13].
Growing evidence indicates that nuclear accumulation of HIF results in transcriptional activation of the vascular endothelial growth factor (VEGF) whose pathway is modulated by reactive oxygen species (ROS), and demonstrating VEGF downregulation following HIF1a gene deletion and that HIF1/2 determined VEGF levels $[4,28,44]$. Francescone et al. identified that YKL-40 (CHI3L1) closely upregulates VEGF expression, and YKL-40-induced tumor vasculogenesis is at least partially dependent on VEGF [21].

\section{Adult stem cells, human subventricular zone and YKL-40 expression in glioblastoma}

In the adult human brain, astrocytes are the largest glial population, and provide structural, metabolic, and trophic support for neurons. Astrocytes can also support proliferation of adult NSCs lining the SVZ. Adult neurogenesis is a lifetime process, which has been isolated from two specific neurogenic regions: the dentate gyrus of the hippocampus, and the subventricular zone of the lateral ventricles. In both regions, NSCS are identified as a subpopulation of astrocytes that are able to produce undifferentiated neuronal and glial precursors [13,18,40,67].

The adult SVZ, most pronounced in the dorsolateral wall of the lateral ventricle, is the main 
source of new neurons in the adult brain, and contains a subset of astrocytes which behave as stem cells both in vivo and in vitro $[18,25,30,43,45,68]$, and derive from radial glia (RG) cells $[17,39]$. In fact, $R G$ cells also act as NSCs and source of neurogenesis, and probably give rise to astrocytes in the cerebral cortex $[17,23,64,74]$. In the adult human brain, the cellular composition and cytoarchitecture of the SVZ is organized into four distinct layers: layer I is found adjacent to the lateral ventricle, and represents a single layer of multi-cialiated ependymal cells; layer II, also known as a hypocellular layer [64], consisting of a diffuse network of a large number of astrocytic, ependymal and neuronal processes, but a few cell bodies; layer III, a strip of astrocytic bodies, and externally, layer IV, adjacent to the brain parenchyma, we find a transition zone composed of many myelin tracts and neuronal bodies (Fig. 2) $[25,26,30,38,57]$.

Interestingly, NSCS, identified as a subpopulation of astrocytes called B1 astrocytes, give rise to actively proliferating transit amplifying progenitors (type $C$ cells), which in turn differentiate into neuroblasts (type A cells) that differentiate into interneurons and eventually migrate toward the olfactory bulb (OB) circuitry, via the rostral migratory stream (RMS), preferentially located in the ventral anterior SVZ of the adult human brain (Fig. 3). In the adult

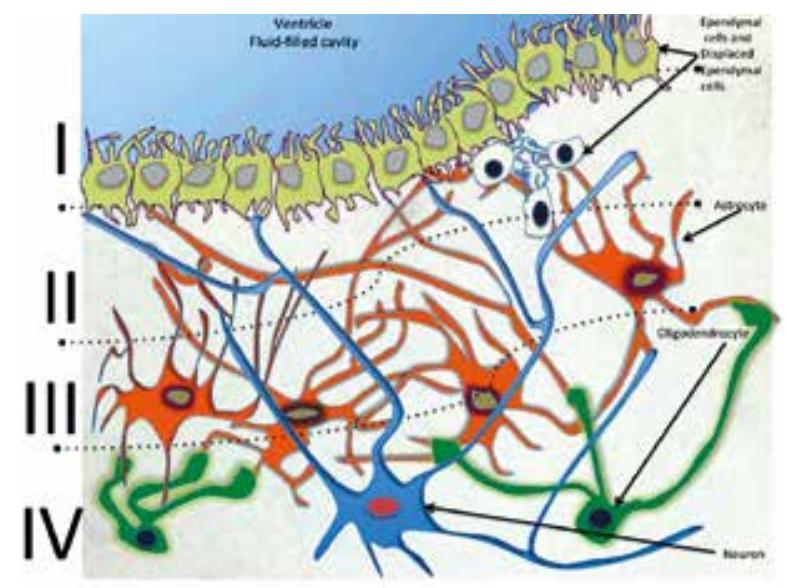

Fig. 2. A diagrammatic sectional view of the human subventricular zone. Lateral ventricle illustrating the cellular composition and cytoarchitecture of subventricular zone (SVZ), consisting of four layers: layer I - ependymal cells, layer II - hypocellular gap, layer III - a strip of astrocyte bodies, and layer IV - transitional zone. human brain, there are a small number of migratory neuroblasts in the SVZ and RMS. Nevertheless, so far there has been no consensus about the exact mechanisms underlying such neural migration toward OB in the adult human SVZ, and also whether there is an RMS $[16,57,65]$. Although the cytoarchitecture of the adult human SVZ have been characterized, a transcriptional analysis has not been fully established and understood. Interestingly, a recent transcriptional analysis [51] distinguished human SVZ astrocytes from parenchymal astrocytes based on gene expression, suggesting that SVZ astrocytes (type B) maintain the stemness in the adult human brain. Alternatively, it was found that in vitro CSCS have a tropism toward normal vasculature.

A putative source of glioma cells is the SVZ, the largest area of neurogenesis in the adult human brain. NSCs line the lateral ventricles in the SVZ, and recruitment of these progenitor cells may play a role in the aggressive behavior encountered in GB. In animal studies, the SVZ demonstrated increased susceptibility to tumorigenesis compared with cortical regions. Experiments and clinical findings provide evidence that neuronal progenitor cells in the SVZ with a high migratory potential are involved in the aggressive GB subtype. Recently, the SVZ has been identified as the source cells of malignant gliomas $[55,63-66,68]$.

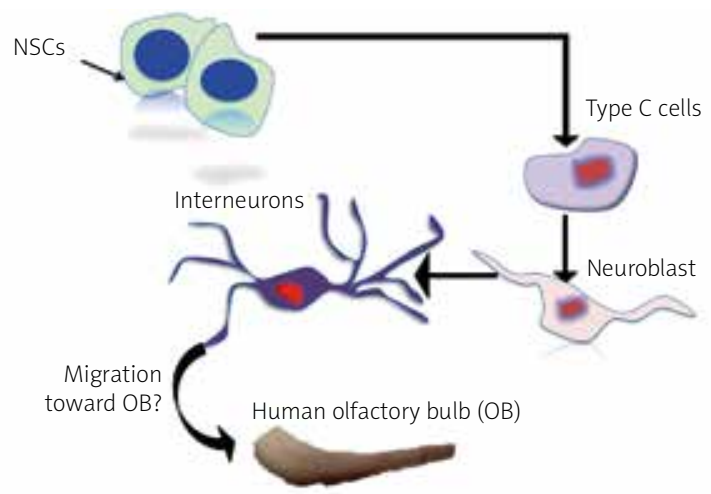

Fig. 3. Cell types and anatomy of the subventricular zone (SVZ) niche. Neural stem cells in the human brain, which generate the type $C$ cells. These transit amplifying cells, type $C$ cells, mature into type A cells, or neuroblasts that differentiate into interneurons and eventually migrate toward the olfactory bulb circuitry, preferentially located in the ventral anterior SVZ of the adult human brain. 
Based on cancer stem cell theory, and images of GB, SVZ was classified according to one of these categories: type I - tumor in which the contrast-enhancing lesion contacts both the SVZ and the cortex; type II - tumor contacts the SVZ but not the cortex; type III - tumor contacts the cortex but not the SVZ, and type IV - tumor contacts neither the SVZ nor the cortex [46]. Regarding the multifocal and/or multicentric GBs there are many theories, but supported by few studies [46,69], showing an association with group I given the findings consistent with high migratory and invasiveness of cells, according to Willis' theory. Although relevant data suggest that GSCs may be important in gliomagenesis originating from SVZ, recent research has differed from this argument, hypothesizing through a combination of clinical observations and mathematical modeling that GBs may arise from cells distributed throughout the white matter and not limited to the region of the SVZ [9].

In a novel and interesting study on the YKL-40 expression in developing human embryonic and fetal tissues conducted by Bjornbak [7], YKL-40 was found to be associated with tissues undergoing morphogenetic changes. In this research, YKL-40 was found significantly marked in $G B$, as compared with normal human brain SVZ. By using immunohistochemical, double-labeling immunofluorescence and mRNA analysis through brain development (from $6^{\text {th }}$ to $21^{\text {st }}$ week post-conception), the authors pointed out that YKL-40 may be implicated in controlling angiogenesis and access of peripheral cells to the forebrain.

On the cellular lever, Bjornbak also suggested that YKL-40 plays a role in the developing brain barriers as well as is possibly involved in the differentiation of a particular astrocytic lineage. Consistent with our previous findings [55], in this study there was a decreased YKL-40 immunoreactivity in proximity to the cortex and ECS of the pia mater were not positive for YKL-40. Additionally, YKL-40 immunoreactivity was found also to be produced by the choroid plexus epithelium and secreted into the ventricular system and either detected in both neuroepithelial cells and radial glial end feet. Strikingly, Antonelly et al. [3] reported on 22 children with GBs who underwent tumor resection and immunohistochemistry was performed on tumor tissue for YKL-40 immunoexpression, showing less expression and better OS. However, such disagreement with recent data may be due to a small sample size, as stated by the authors.

Recent studies with gene expression profiles have established that cells expressing increased mesenchymal properties have a tendency to display selfrenewal capacity. Interestingly, mesenchymal signature genes such as YKL-40 (shown in the early stage of development and probably related to neural stem cells) and oncostatin $\mathrm{M}$ - which belongs to interleukin 6 group of cytokines - receptor are associated with highly invasive feature and worse prognosis in GB patients [49,72].

Current data provide several useful insights $[47,71]$. First, YKL-40-positive cells may be responsible for the aggressive and invasive pattern seen in GSC. What are the properties of the microenvironment that permit widespread invasion? The previous phenomenon probably could be mediated by NSCS cues or by direct response of YKL-40 over ECs. Since most GBs tumors occur late in life and recently it was suggested a relationship between YKL-40 and SVZ, we can estimate that GBs could be initiated either by unknown trigger factors over preformed pathways. As regards YKL-40 immunoexpression, is there a special association between SVZ regionalization and GB formation? Under this topic, further studies in large series are needed to evaluate how YKL-40 measurements and pathways change throughout life. Furthermore, currently we are conducting a study that seeks to determine the factors causing tumor YKL-40 overexpression and whether such factors are expressed in both SVZ in close relationship to GB and in SVZ without a close relationship with $G B$ in the same brain patients.

\section{The role of YKL-40, glial cells and perivascular scaffold in migration and invasion}

The existence of possible anatomical scaffolds allowing motility and migration of neuronal precursors toward the olfactory bulb along the vessels was first suggested and reported by Bovetti et al. [11] based on experimental analysis of olfactory bulb $(\mathrm{OB})$ in rodents. Ontogenically, RG cells have been described as the first glia to appear, developing probably from the neuroepithelial youngest cells [17].

Although RG cells maintain a close contact with the SVZ in humans throughout adulthood, its apical processes are shortened by a probable retractable 
mechanism with posterior acquisition of ependymal characteristics, suggesting that RG cells turn into astrocytes, carried out by a mechanism not well understood [10,75], although the factors responsible for radial glia and their maintenance are lost during development.

Even though the existence of neuronal migration along RG during development is patent, in the mammalian adulthood such phenomenon is not experimentally demonstrated. Based on the latter findings, recent research suggests that heterotopic RG cells progeny spread at early postnatal stages with local proliferation [17].

We hypothesize that GB tumors regionalization in adult human brain could be explained by the fact that residual RG-tumor promoter could be 'lost' in different brain pathways, but given the technical difficulty following stem cells along the extension of the RG cells and to determine the microanatomic localization of perivascular glioma cells, the invasive and motility pattern of gliomas may be explained nowadays by the understanding of branching blood vessel architecture. The study of all mechanisms that control and modulate the migration and invasion of GSCs and progeny is a crucial step for the design of therapies against $\mathrm{GB}$.

Baker et al. [4] studied the requirement for neoangiogenesis in perivascular glioma by treating animals with angiogenesis inhibitors bevacizumab and DC101. In their work, the authors explained that perivascular invasion give rise to neoangiogenesis by digesting normal brain tissue in a VEGF-independent way that leads to tumor invasion. In line with a vascular-guided GSCs migration pattern during GB progression, Shao et al., reviewed how the mesenchymal marker YKL-40 acts on GSCs to lead to the formation of angiogenesis. They explained that YKL-40 maintains vascular integrity. This fact is of paramount relevance as the microanatomic vascular scaffold was long thought to be non-neoplastic and that the relationship between tumor cells and ECs are independent [20].

\section{Conclusions}

Glioblastoma with SVZ infiltration showed decreased PFS and OS rates, probably due to GSCs and its aggressive mesenchymal growth pattern. YKL-40 seems to play a key role in the motility and migrating patterns of GSCs and their transdifferentiation into ECs. These findings may be associated with the loca- tion of GSCs in the SVZ and the occurrence of a more invasive and migratory GB subtype. Furthermore, GSCs can be the source for inter-tumoral heterogeneity with an impact on clinical outcome.

Although tumor development is highly dependent of several molecular factors, angiogenesis may be the key to developing novel therapeutic agents able to inhibit molecular pathways responsible for GB.

\section{Disclosure}

Authors report no conflict of interest.

\section{References}

1. Abraham S, Hu N, Jensen R. Hypoxia-inducible factor-1-regulated protein expression and oligodendroglioma patient outcome: comparison with established biomarkers and preoperative UCSF low-grade scoring system. J Neurooncol 2012; 108: 459-468.

2. Akiyama Y, Ashizawa T, Komiyama M, Miyata H, Oshita C, Omiya M, lizuka A, Kume A, Sugino T, Hayashi N, Mitsuya K, Nakasu Y, Yamaguchi K. YKL-40 downregulation is a key factor to overcome temozolomide resistance in a glioblastoma cell line. Oncol Rep 2014; 32: 159-166.

3. Antonelli M, Buttarelli FR, Arcella A, Nobusawa S, Donofrio V, Oghaki H, Giangaspero F. Prognostic significance of histological grading, p53 status, YKL-40 expression, and IDH1 mutations in pediatric high-grade gliomas. J Neurooncol 2010; 99: 209-215.

4. Baker GJ, Yadav VN, Motsch S, Koschmann C, Calinescu AA, Mineharu Y, Camelo-Piragua SI, Orringer D, Bannykh S, Nichols WS, deCarvalho AC, Mikkelsen T, Castro MG, Lowenstein PR. Mechanisms of glioma formation: iterative perivascular glioma growth and invasion leads to tumor progression, VEGF-independent vascularization, and resistance to antiangiogenic therapy. Neoplasia 2014; 16: 543-561.

5. Barami K, Sloan AE, Rojiani A, Schell MJ, Staller A, Brem S. Relationship of gliomas to the ventricular walls. J Clin Neurosci 2009; 16: 195-201.

6. Barciszewska AM. MicroRNAs as efficient biomarkers in highgrade gliomas. Folia Neuropathol 2016; 54: 351-359.

7. Bernardi D, Padoan A, Ballin A, Sartori M, Manara R, Scienza R, Plebani M, Della Puppa A. Serum YKL-40 following resection for cerebral glioblastoma. J Neurooncol 2011; 107: 299-305.

8. Bjornbak C, Brochner CB, Larsen LA, Johansen JS, Mollgard K. Brain barriers and a subpopulation of astroglial progenitors of developing human forebrain are immunostained for the glycoprotein YKL-40. J Histochem Cytochem 2014; 62: 369-388.

9. Bleeker FE, Molenaar RJ, Leenstra S. Recent advances in the molecular understanding of glioblastoma. Journal Neurooncol 2012; 108: 11-27.

10. Bohman LE, Swanson KR, Moore JL, Rockne R, Mandigo C, Hankinson T, Assanah M, Canoll P, Bruce JN. Magnetic Resonance Imaging Characteristics of Glioblastoma Multiforme: Implications for Understanding Glioma Ontogeny. Neurosurgery 2010; 67: 1319-1328. 
11. Bovetti S, Hsieh YC, Bovolin P, Perroteau I, Kazunori T, Puche AC. Blood vessels form a scaffold for neuroblast migration in the adult olfactory bulb. J Neurosci 2007; 27: 5976-5980.

12. Brooks MD, Sengupta R, Snyder SC, Rubin JB. Hitting Them Where They Live: Targeting the Glioblastoma Perivascular Stem Cell Niche. Curr Pathobiol Rep 2013; 1: 101-110.

13. Calabrese C, Poppleton H, Kocak M, Hogg TL, Fuller C, Hamner B, Oh EY, Gaber MW, Finklestein D, Allen M, Frank A, Bayazitov IT, Zakharenko SS, Gajjar A, Davidoff A, Gilbertson RJ. A perivascular niche for brain tumor stem cells. Cancer Cell 2007; 11: 69-82.

14. Chen J, Li Y, Yu TS, McKay RM, Burns DK, Kernie SG, Parada LF. A restricted cell population propagates glioblastoma growth after chemotherapy. Nature 2012; 488: 522-526.

15. Cheng L, Bao S, Rich JN. Potential therapeutic implications of cancer stem cells in glioblastoma. Biochem Pharmacol 2010; 80: 654-665.

16. Colman H, Zhang L, Sulman EP, McDonald JM, Shooshtari NL, Rivera A, Popoff S, Nutt CL, Louis DN, Cairncross JG, Gilbert MR, Phillips HS, Mehta MP, Chakravarti A, Pelloski CE, Bhat K, Feuerstein BG, Jenkins RB, Aldape K. A multigene predictor of outcome in glioblastoma. Neurooncol 2010; 12: 49-57.

17. Curtis MA, Kam M, Nannmark U, Anderson MF, Axell MZ, Wik kelso C, Holtås S, van Roon-Mom WM, Björk-Eriksson T, Nordborg C, Frisén J, Dragunow M, Faull RL, Eriksson PS. Human neuroblasts migrate to the olfactory bulb via a lateral ventricular extension. Science 2007; 315: 1243-1249.

18. Dimou L, Gotz M. Glial cells as progenitors and stem cells: new roles in the healthy and diseased brain. Physiol Rev 2014; 94 709-737.

19. Doetsch F, Caillé I, Lim DA, García-Verdugo JMG, Alvarez-Buylla A. Subventricular zone astrocytes are neural stem cells in the adult mammalian brain. Cell 1999; 97: 703-716.

20. Ellison DW, Steart PV, Bateman AC, Pickering RM, Palmer J, Weller RO. Prognostic indicators in a range of astrocytic tumours: an immunohistochemical study with Ki-67 and p53 antibodies. J Neurol Neurosurg Psychiatry 1995; 59: 413-419.

21. Folkman J, Merler E, Abernathy C, Williams G. Isolation of a tumor factor responsible for angiogenesis. J Exp Med 1971; 133: 275-288.

22. Francescone RA, Scully S, Faibish M, Taylor SL, Oh D, Moral L Yan W, Bentley B, Shao R. Role of YKL-40 in the angiogenesis, radioresistance, and progression of glioblastoma. J Biol Chem 2011; 286: 15332-15343.

23. Galli R, Binda E, Orfanelli U, Cipelletti B, Gritti A, De Vitis S, Fiocco R, Foroni C, Dimeco F, Vescovi A. Isolation and characterization of tumorigenic, stem-like neural precursors from human glioblastoma. Cancer Res 2004; 64: 7011-7021.

24. Ge WP, Jia JM. Local production of astrocytes in the cerebral cortex. Neuroscience 2016; 323: 1-7.

25. Ghazi SO, Stark M, Zhao Z, Mobley BC, Munden A, Hover L, Abel TW. Cell of origin determines tumor phenotype in an oncogenic Ras/ p53 knockout transgenic model of high-grade glioma. J Neuropathol Exp Neurol 2012; 71: 729-740.

26. Gonzalez-Perez O, Garcia-Verdugo JM, Quinones-Hinojosa A Luquin S, Gudino-Cabrera G, Gonzalez-Castaneda RE. Neura stem cells in the adult brain: from benchside to clinic. Stem Cells Int 2012; 2012: 378356
27. Gonzalez-Perez O. Neural stem cells in the adult human brain. Biol Biomed Rep 2012; 2: 59-69.

28. Gursel DB, Beyene RT, Hofstetter C, Greenfield JP, Souweidane MM, Kaplitt M, Arango-Lievano M, Howard B, Boockvar JA. Optimization of glioblastoma multiforme stem cell isolation, transfection, and transduction. J Neurooncol 2011; 104: 509-522.

29. Heddleston JM, Li Z, Hjelmeland AB, Rich JN. The hypoxic microenvironment maintains glioblastoma stem cells and promotes reprogramming towards a cancer stem cell phenotype. Cell Cycle 2009; 20: 3274-3284.

30. Hormigo A, Gu B, Karimi S, Riedel E, Panageas KS, Edgar MA, Tanwar MK, Rao JS, Fleisher M, DeAngelis LM, Holland EC. YKL-40 and matrix metalloproteinase- 9 as potential serum biomarkers for patients with high-grade gliomas. Clin Cancer Res 2006; 12: 5698-5704

31. Ihrie RA, Alvarez-buylla A. Lake-front property: a unique germinal niche by the lateral ventricles of the adult brain. Neuron 2011; 70: 674-686.

32. Iwamoto FM, Hormigo A. Unveiling YKL-40, from serum marker to target therapy in glioblastoma. Front Oncol 2014; 4: 90.

33. Iwamoto FM, Hottinger AF, Karimi S, Riedel E, Dantis J, Jahdi M, Panageas KS, Lassman AB, Abrey LE, Fleisher M, DeAngelis LM, Holland EC, Hormigo A. Serum YKL-40 is a marker of prognosis and disease status in high-grade gliomas. Neurooncol 2011; 13 : 1244-1251.

34. Jafri NF, Clarke JL, Weinberg V, Barani IJ, Cha S. Relationship of glioblatoma multiforme to the subventricular zone is associated with survival. Neurooncol 2013; 15: 91-96.

35. Jhaveri N, Chen TC, Hofman FM. Tumor vasculature and glioma stem cells: contributions to glioma progression. Cancer Lett 2016; 380: 545-551.

36. Johansen JS, Cintin C, Jørgensen M, Kamby C, Price PA. Serum YKL-40: a new potential marker of prognosis and location of metastases of patients with recurrent breast cancer. Eur J Cancer 1995; 31: 1437-1442.

37. Joseph JV, Conroy S, Pavlov K, Sontakke P, Tomar T, Eggens-Meijer E, Balasubramaniyan V, Wagemakers M, den Dunnen WF, Kruyt FA. Hypoxia enhances migration and invasion in glioblastoma by promoting a mesenchymal shift mediated by the HIF1 $\alpha$-ZEB1 axis. Cancer Lett 2015; 359: 107-116.

38. Kimura M, Lee Y, Miller R, Castillo M. Glioblastoma multiforme: relationship to subventricular zone and recurrence. Neuroradiol J 2013; 26: 542-547.

39. Kotagiri P, Chance SA, Szele FG, Esiri MM. Subventricular zone cytoarchitecture changes in Autism. Dev Neurobiol 2013; 74: 25-41.

40. Kriegstein A, Alvarez-Buylla A. The glial nature of embryonic and adult neural stem cells. Annu Rev Neurosci 2009; 32: 149-184.

41. Lacar B, Herman P, Platel JC, Kubera C, Hyder F, Bordey A. Neural Progenitor Cells Regulate Capillary Blood Flow in the Postnatal Subventricular Zone. J Neurosci 2012; 32: 16435-16448.

42. Lamborn KR. Prognostic factors for survival of patients with glioblastoma: Recursive partitioning analysis. Neurooncol 2004; 6: 227-235.

43. Lathia JD, Mack SC, Mulkearns-Hubert EE, Valentim CL, Rich JN. Cancer stem cells in glioblastoma. Genes Dev 2015; 29: 1203-1217.

44. Laywell ED, Rakic P, Kukekov VG, Holland EC, Steindler DA. Identification of a multipotent astrocytic stem cell in the imma- 
ture and adult mouse brain. Proc Natl Acad Sci USA 2000; 97 : 13883-13888

45. Li L, Candelario KM, Thomas K, Wang R, Wright K, Messier A, Cunningham LA. Hypoxia Inducible Factor-1 (HIF-1) Is Required for Neural Stem Cell Maintenance and Vascular Stability in the Adult Mouse SVZ. J Neurosci 2014; 34: 16713-16719.

46. Lim DA, Alvarez-Buylla A. Adult neural stem cells stake their ground. Trends Neurosci 2014; 37: 563-571.

47. Lim DA, Cha S, Mayo MC, Chen MH, Keles E, VandenBerg S, Berger MS. Relationship of glioblastoma multiforme to neural stem cell regions predicts invasive and multifocal tumor phenotype. Neuro Oncol 2007; 9: 424-429.

48. Liu Y, Ye F, Yamada K, Tso JL, Zhang Y, Nguyen DH, Dong Q, Soto H, Choe J, Dembo A, Wheeler H, Eskin A, Schmid I, Yong WH, Mischel PS, Cloughesy TF, Kornblum HI, Nelson SF, Liau LM, Tso CL. Autocrine endothelin-3/endothelin receptor B signaling maintains cellular and molecular properties of glioblastoma stem cells. Mol Cancer Res 2011; 9: 1668-1685.

49. Michaelsen SR, Christensen IJ, Grunnet K, Stockhausen M-TRS, Broholm H, Kosteljanetz M, Poulsen HS. Clinical variables serve as prognostic factors in a model for survival from glioblastoma multiforme: an observational study of a cohort of consecutive non-selected patients from a single institution. BMC Cancer 2013; 13: 402.

50. Natesh K, Bhosale D, Desai A, Chandrika G, Pujari R, Jagtap J, Chugh A, Ranade D, Shastry P. Oncostatin-M differentially regulates mesenchymal and proneural signature genes in gliomas via STAT3 signaling. Neoplasia 2015; 17: 225-237.

51. Nduom EK, Hadjipanayis CG, Van Meir EG. Glioblastoma cancer stem-like cells: implications for pathogenesis and treatment. Cancer I 2012; 18: 100-106.

52. Oldham MC, Konopka G, Iwamoto K, Langfelder P, Kato T, Horvath S, Geschwind DH. Functional organization of the transcriptome in human brain. Nat Neurosci 2008; 11: 1271-1282.

53. Ostrom QT, Gittleman H, Liao P, Rouse C, Chen Y, Dowling J, Wolinsky Y, Kruchko C, Barnholtz-Sloan J. CBTRUS statistical report: primary brain and central nervous system tumors diagnosed in the United States in 2007-2011. Neuro Oncol 2014; 16 Suppl 4: iv1-iv63.

54. Pelloski CE, Lin E, Zhang L, Yung WKA, Colman H, Liu JL, Woo SY, Heimberger AB, Suki D, Prados M, Chang S, Barker FG 3rd, Fuller GN, Aldape KD. Prognostic associations of activated mitogen-activated protein kinase and Akt pathways in glioblastoma. Clin Cancer Res 2006; 12: 3935-3941.

55. Pelloski CE, Mahajan A, Maor M, Chang EL, Woo S, Gilbert M Colman H, Liu JL, Woo SY, Heimberger AB, Suki D, Prados M, Chang S, Barker FG 3rd, Fuller GN, Aldape KD. YKL-40 expression is associated with poorer response to radiation and shorter overall survival in glioblastoma. Clin Cancer Res 2005; 11: 3326-3334.

56. Piña Batista KM, Fernandez Vega I, Alvarez de Eulate-Beramendi S, Gutierrez Morales JC, Kurbanov A, Asnel D, Meilan A, Astudillo A. Prognostic significance of the markers IDH1 and YKL40 related to the subventricular zone. Folia Neuropathol 2015; 53: 52-59.

57. Piña Batista KM, Lourenco Costa BA, Cuervo-Arango Herreros I, Fernandez Vega I, Gutierrez Morales JC, Vallina Álvarez A, Mar- ron PI, Meilán A, Astudillo A, Alvarez KY. Analysis of Olig2 and YKL-40 expression: a clinicopathological/immunohistochemical study for the distinction between subventricular zone II and III glioblastomas. Folia Neuropathol 2016; 54: 31-39.

58. Ping YF, Zhang X, Bian XW. Cancer stem cells and their vascular niche: Do they benefit from each other? Cancer Lett 2016; 380: 561-567.

59. Quinones-Hinojosa A, Sanai N, Soriano-Navarro M, GonzalezPerez O, Mirzadeh Z, Gil-Perotin S, Romero-Rodriguez R, Berger MS, Garcia-Verdugo JM, Alvarez-Buylla A. Cellular composition and cytoarchitecture of the adult human subventricular zone: a niche of neural stem cells. J Comp Neurol 2006; 494: 415-434.

60. Rath BH, Fair JM, Jamal M, Camphausen K, Tofilon PJ. Astrocytes enhance the invasion potential of glioblastoma stem-like cells. PLoS One 2013; 8: e54752.

61. Reardon DA, Wen PY, Desjardins A, Batchelor TT, Vredenburgh JJ. Glioblastoma multiforme: an emerging paradigm of anti-VEGF therapy. Expert Opin Biol Ther 2008; 8: 541-553.

62. Ricci-Vitiani L, Pallini R, Biffoni M, Todaro M, Invernici G, Cenci T, Maira G, Parati EA, Stassi G, Larocca LM, De Maria R. Tumour vascularization via endothelial differentiation of glioblastoma stemlike cells. Nature 2010; 468: 824-828.

63. Rodriguez FJ, Orr BA, Ligon KL, Eberhart CG. Neoplastic cells are a rare component in human glioblastoma microvasculature. Oncotarget 2012; 3: 98-106.

64. Safa AR, Saadatzadeh MR, Cohen-Gadol AA, Pollok KE, BijangiVishehsaraei K. Glioblastoma stem cells (GSCs) epigenetic plasticity and interconversion between differentiated non-GSCs and GSCs. Genes Dis 2015; 2: 152-163.

65. Sanai N, Alvarez-buylla A, Berger MS. Neural stem cells and the origin of gliomas. N Engl J Med 2005; 353: 811-822.

66. Sanai N, Nguyen T, Ihrie RA, Mirzadeh Z, Tsai HH, Wong M, Gupta N, Berger MS, Huang E, Garcia-Verdugo JM, Rowitch DH, Alvarez-Buylla A. Corridors of migrating neurons in the human brain and their decline during infancy. Nature 2012; 478: 382-386.

67. Sanai N, Tramontin AD, Quinones-Hinojosa A, Barbaro NM, Gupta N, Kunwar S, Lawton MT, McDermott MW, Parsa AT, Manuel-García Verdugo J, Berger MS, Alvarez-Buylla A. Unique astrocyte ribbon in adult human brain contains neural stem cells but lacks chain migration. Nature 2004; 427: 740-744.

68. Schiffer D, Mellai M, Annovazzi L, Caldera V, Piazzi A, Denysenko T, Melcarne A. Stem cell niches in glioblastoma: a neuropathological view. Biomed Res Int 2014; 2014: 725921.

69. Segarra M, Kirchmaier BC, Acker-Palmer A. A vascular perspective on neuronal migration. Mech Dev 2015; 138 Pt 1: 17-25.

70. Sequerra EB. Subventricular zone progenitors in time and space: generating neuronal diversity. Front Cell Neurosci 2014; 8: 434.

71. Shakur SF, Bit-Ivan E, Watkin WG, Merrell RT, Farhat HI. Multifocal and multicentric glioblastoma with leptomeningeal gliomatosis: a case report and review of the literature. Case Rep Med 2013; 2013: 132679.

72. Shao R, Francescone RA, Ngernyuang N, Bentley B, Taylor SL, Moral L, Yan W. Anti-YKL-40 antibody and ionizing irradiation synergistically inhibit tumor vascularization and malignancy in glioblastoma. Carcinogenesis 2014; 35: 373-382. 
Kelvin M. Piña Batista, Sayoa Alvarez de Eulate-Beramendi, Kenia Y. Álvarez Reyes de Piña, Pedro Reimunde Figueira, Adan Fernandez Canal, Josué M. Avecillas Chasin, Ángela Meilan, Rodrigo Ugalde, Ivan Fernandez Vega

73. Shao R, Taylor SL, Oh DS, Schwartz LM. Vascular heterogeneity and targeting: the role of YKL-40 in glioblastoma vascularization. Oncotarget 2015; 6: 40507-40518.

74. Singh SK, Bhardwaj R, Wilczynska KM, Dumur Cl, Kordula T. A complex of nuclear factor I-X3 and STAT3 regulates astrocyte and glioma migration through the secreted glycoprotein YKL-40. J Biol Chem 2011; 286: 39893-39903.

75. Soeda A, Hara A, Kunisada T, Yoshimura SI, Iwama T, Park DM. The evidence of glioblastoma heterogeneity. Sci Rep 2015; 5: 9630.

76. Spalding KL, Bergmann O, Alkass K, Bernard S, Salehpour M, Huttner HB, Bostrom E, Westerlund I, Vial C, Buchholz BA, Possnert G, Mash DC, Druid H, Frisen J. Dynamics of hippocampal neurogenesis in adult humans. Cell 2013; 6: 1219-1227.

77. Spassky N, Merkle FT, Flames N, Tramontin AD, Garcia-Verdugo JM, Alvarez-Buylla A. Adult ependymal cells are postmitotic and are derived from radial glial cells during embryogenesis. J Neurosci 2005; 25: 10-18.

78. Stiles CD, Rowitch DH. Glioma stem cells: a midterm exam. Neuron 2008; 58: 832-846.

79. Stupp R, Pavlidis N, Jelic S; ESMO Guidelines Task Force. ESMO Minimum Clinical Recommendations for diagnosis, treatment and follow-up of malignant glioma. Ann Oncol 2005; 16 Suppl 1: i64-65.

80. Thomas RP, Xu LW, Lober RM, Li G, Nagpal S. The incidence and significance of multiple lesions in glioblastoma. J Neuroonco 2013; 112: 91-97.

81. Tran B, Rosenthal MA. Survival comparison between glioblastoma multiforme and other incurable cancers. J Clin Neurosci 2010; 17: 417-421.

82. Tso IL, Yang S, Menjivar JC, Yamada K, Zhang Y, Hong I, Bui Y, Stream A, McBride WH, Liau LM, Nelson SF, Cloughesy TF, Yong WH, Lai A, Tso CL Bone morphogenetic protein 7 sensitizes 06-methylguanine methyltransferase expressing-glioblastoma stem cells to clinically relevant dose of temozolomide. Mol Cancer 2015; 14: 189.

83. Van Meir EG, Hadjipanayis CG, Norden AD, Shu HK, Wen PY, Olson JJ. Exciting new advances in neuro-oncology: the avenue to a cure for malignant glioma. Cancer J Clin 2010; 60: 166-193.

84. Wang R, Chadalavada K, Wilshire J, Kowalik U, Hovinga KE, Geber A, Fligelman B, Leversha M, Brennan C, Tabar V. Glioblastoma stem-like cells give rise to tumour endothelium. Nature 2010; 468: 829-833.

85. Yan K, Yang K, Rich JN. The evolving landscape of glioblastoma stem cells. Curr Opin Neurol 2013; 26: 701-707.

86. Zhang S, Lai N, Liao K, Sun J, Lin Y. MicroRNA-210 regulates cell proliferation and apoptosis by targeting regulator of differentiation 1 in glioblastoma cells. Folia Neuropathol 2015; 53: 236-244.

87. Zhang W, Kawanishi M, Miyake K, Kagawa M, Kawai N, Murao K, Nishiyama A, Fei Z, Zhang X, Tamiya T. Association between YKL-40 and adult primary astrocytoma. Cancer 2010; 116: 26882697. 